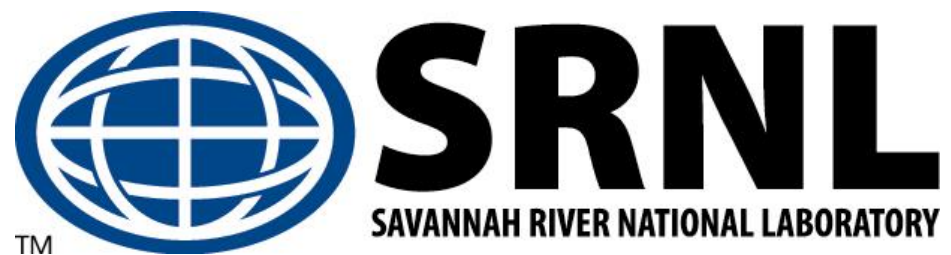

SRNL-STI-2011-00347

\title{
Effect of Pore Size on Trapping Zinc Vapors
}

\author{
Paul Korinko
}

December 17, 2010

\section{Savannah River National Laboratory Savannah River Nuclear Solutions Savannah River Site Aiken, South Carolina}

This document was prepared in connection with work done under Contract No. DE-AC09-08SR22470 with the U.S. Department of Energy. By acceptance of this document, the publisher and/or recipient acknowledges the U.S. Government's right to retain a nonexclusive, royalty-free license in and to any copyright covering this document, along with the right to reproduce and authorize others to reproduce all or part of the copyrighted material. 


\section{SRNL-STI-2011-00347}

\section{Effect of Pore Size on Trapping Zinc Vapors}

\section{Table of Contents}

Summary

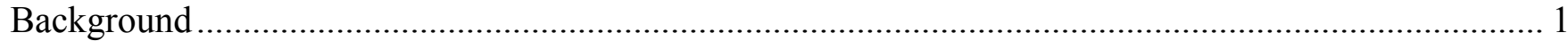

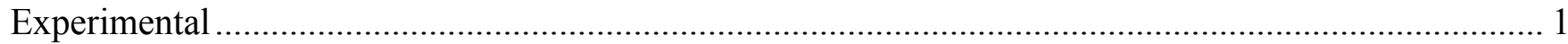

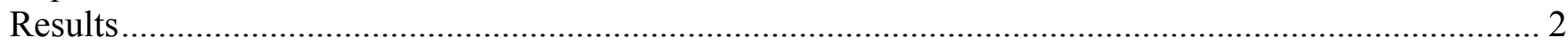

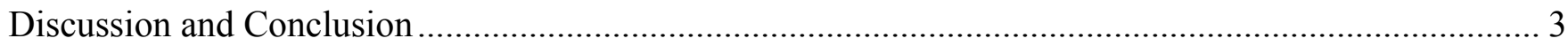

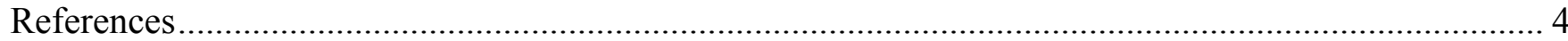

\section{List of Tables}

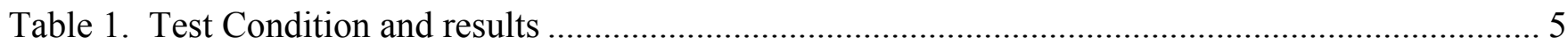

\section{List of Figures}

Figure 1. Photographs of zinc TVD apparatus, initial and final configurations, installed in chemical hood

Figure 2. Evacuation times for the original apparatus with filters of $0.2 \mu \mathrm{m}$ and $1 \mu \mathrm{m}$ installed.

Figure 3. Evacuation times for the original apparatus with filters with 5, 10, and $20 \mu \mathrm{m}$ installed......... 8

Figure 4 Typical data for the experimental evolution starting with filter element heating. .................... 9

Figure 5. Comparison data from all five sized filter pores. ...................................................... 10

Figure 6. Macrograph of a rod exposed to the vapor and temperature gradient in TVD \#1. Letters indicate areas of higher magnification images in Figure 7 ..................................................... 11

Figure 7. Higher magnification of the various morphologies on the rod...................................... 12

Figure 8. Higher magnification of area " $D$ " showing the mixed mode growth at the cool end of the rod.

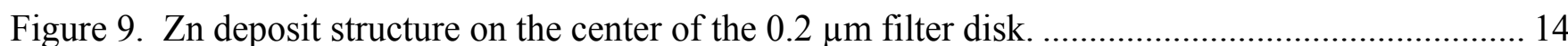

Figure 10. Zn deposit structure on the $20 \mu \mathrm{m}$ filter disk. ....................................................... 15

Figure 11. Plot of mass change as function of pore size with experimental conditions also indicated... 16

Figure 12. Condition of thermally treated zinc (a) and as received (b) zinc. ................................... 17 


\section{Effect of Pore Size on Trapping Zinc Vapors}

\section{Summary}

A series of experiments were conducted to determine the effect of pore size on pumping efficiency and zinc vapor trapping efficiency. A simple pumping efficiency test was conducted for all five pore diameters where it was observed that evacuation times were adversely affected by reducing the pore size below $5 \mu \mathrm{m}$. Common test conditions for the zinc trapping efficiency experiments were used. These conditions resulted in some variability, to ascribe different efficiencies to the filter media. However, the data suggest that there is no significant difference in trapping efficiency for filter media with pores from 0.2 to $20 \mu \mathrm{m}$ with a thickness of 0.065 ". Consequently, the $20 \mu \mathrm{m}$ pore filter media that is currently used at SRS is a suitable filter material for to utilize for future extractions. There is evidence that smaller pore filter will adversely affect the pumping times for the TEF and little evidence to suggest that a smaller pore diameters have significant impact on the trapping efficiency.

\section{Background}

An experimental program was initiated in order to develop a validate conditions that will effectively trap $\mathrm{Zn}$ vapors that are released during extraction. The proposed work is broken down into three tasks. The first task is to determine the effectiveness of various pore sizes of filter elements. The second task is to determine the effect of filter temperature on zinc vapor deposition. The final task is to determine whether the zinc vapors can be chemically bound. The approach for chemically binding the zinc vapors has two subtasks, the first is a review of literature and thermodynamic calculations and the second is an experimental approach using the best candidates. This report details the results of experimental testing to determine the effects of filter pore size on zinc vapor capture (1)

It is known that radioactive zinc $65\left({ }^{65} \mathrm{Zn}\right)$ is extracted from the irradiated TPBARs. Review of the potential sources of ${ }^{65} \mathrm{Zn}$ from the TPBAR sub-elements indicates that it is an activation product of natural zinc and that it is present as a low level contaminant in several of the TPBAR materials $(2,3, \&$ 4). The amounts that are extracted are small but are easily detected due to the gamma radiation that they produce.

A previous task was conducted to determine the morphology of the zinc deposit and a recommendation was made as to temperature and material (5). Based on this recommendation and the availability of materials, $20 \mu \mathrm{m}$ filters were installed in key areas of the TEF process lines. The post-mortem of the filters indicated that some ${ }^{65} \mathrm{Zn}$ had been trapped in these locations, although it was difficult to quantify due to the presence of native $\mathrm{Zn}$ on the filters (6).

\section{Experimental}

Mott filter sample coupons $70 \mathrm{~mm}$ in diameter with pores at 20,10,5,1, and $0.2 \mu \mathrm{m}$ were procured. The filters were used to determine the effect of pore size on pumping time and then used to determine 
the effect of pore size on trapping efficiency. The filters were weighed on a five place Sartorius analytical balance before and after exposure to determine the trapping effectiveness.

Two experimental apparatus for thermal vapor deposition (TVD) of zinc comprised of a heated vessel, instrumentation and heated filter element were assembled as shown in Figure 1; the second apparatus was developed to shorten the distance from the filter to the vessel. The filter element holder is a standard component from Mott Corporation, the manufacturer of the filter elements that are used in the tritium facility. A standard 2 inch diameter filter coupon is sealed within the housing. A scroll pump was used to evacuate the system to pressures of 30 to 80 milliTorr prior to testing. The vessel was evacuated for a minimum of one hour and the pressure was monitored using computer data acquisition. For deposition testing, the system was evacuated for a minimum of one hour prior to heating the filter housing to a set point of $200^{\circ} \mathrm{C}$. The mantle surrounding the flask was then heated to $400^{\circ} \mathrm{C}$. This mantle temperature results in an internal temperature of approximately $320^{\circ} \mathrm{C}$. It had been previously determined that an internal temperature of at least $300^{\circ} \mathrm{C}$ was required to obtain a reasonable zinc pressure. The mantle was programmed to hold the temperature for 120 minutes. The internal vessel temperature was reduced to below $280^{\circ} \mathrm{C}$ prior to cooling the filter. It was desired to maintain the nominal filter deposit temperature as long as the zinc could vaporize. The data were logged using several programs and compiled into a single file for evaluation (7).

The effect of the pore diameter on system evacuation was determined, and the effectiveness of pore diameter on $\mathrm{Zn}$ capture was determined.

\section{Results}

The effect, or lack thereof, of pore size on evacuation time can be seen in Figures 2 and 3. For the 0.2 and $1 \mu \mathrm{m}$ pore filters there is a measurable increase in time required to fully evacuate the apparatus to the final pressure. While the increase is not terribly significant for the approximately 1.5 liter system, when the system volume for TEF is considered, the increased time could be substantial. Figure 3 shows that pores with greater than $5 \mu \mathrm{m}$ do not appear to have an adverse effect on evacuation time as these data all virtually directly overlay the filter free data set.

Despite the required increased time for pumping all five filter diameters were subsequently used for the TVD process. This research was undertaken to determine if the pore size had an effect on the deposition efficiency for a vapor plume that is significantly greater (milligrams/hour) than what is observed in the TEF (nanograms/week).

Upon completion of the pump-down testing, the apparatus was tested with zinc (get specification) and various times and temperatures were tested until a common test condition of $200^{\circ} \mathrm{C}$ for 3 hours for the filter and $400^{\circ} \mathrm{C}$ for 2 hours for the vessel. These conditions provided an mass gains on the filter of approximately $2 \mathrm{mg}$.

A typical test exhibited increases in temperature and pressure as shown in Figure 4 for the $10 \mu \mathrm{m}$ filter. This filter and mantle were heated at approximately $10^{\circ} \mathrm{C} / \mathrm{min}$ to the set point. The pressure started to increase after about 15 minutes at temperature. This behavior was consistent for all the filter sizes and does not seem to bear much relationship to the testing conditions or filter media present. All of the data 
from the filters are shown in Figure 5. These data show this trend with the pressure increase and no relationship to pore size.

The morphology of the deposit both on a stainless steel pin inserted into the vessel and on several filters held at $200^{\circ} \mathrm{C}$ was also investigated. The stainless steel pin is shown in the macrophotograph of Figure 6. There are whiskers clearly visible on this sample, tested using the first apparatus. The deposit was examined using a scanning electron microscope and the details of the deposit can be more clearly seen in Figure 7. There is a different morphology along the rod. The temperature along the rod was determined in a subsequent test and ranged from about 50 to $300^{\circ} \mathrm{C}$. Figure $7 \mathrm{~A}$ shows the morphology of the deposit at the hottest section of the rod where an incomplete coating is formed Figure 7B and Figure $7 \mathrm{C}$ show a full coverage coating with long whiskers that have a hexagonal shape. This shape product is consistent with that developed in the previous task ( ). The coating was also the thickest in this center area that had a temperature between 150 and $250^{\circ} \mathrm{C}$. The coolest area of the rod had a mixed coating morphology. The lower magnification image, Figure 7D, shows some missing areas. A higher magnification image of the deposit in this area is shown in Figure 8. At the higher magnification one can see the hexagonal morphology intermixed with what had previously been called a granular structure.

In addition to the rod suspended in the evacuation vessel, the deposit formed on the 20 and 0.2 micron filters that were exposed at $200^{\circ} \mathrm{C}$ for nominally one hour were examined using the SEM and energy dispersive spectroscopy (EDS). The deposit morphology for both pore sized filters, Figures 9 and 10 was similar with discrete islands of pure $\mathrm{Zn}$ deposited in various locations on the filters. The morphology of the zinc deposit was difficult to clearly image, but it appears to be consistent with that exhibited at the cool end of the rod, without the hexagonal structure that was typically developed at $200^{\circ} \mathrm{C}$.

The weight gain for each of the different filters is listed in Table 1. The data indicate that the time at temperature is more important since tests of shorter duration consistently produced lower weight gains. Due to the variations in the actual experimental conditions with the fluctuations in actual vessel temperatures and times above $300^{\circ} \mathrm{C}$, makes it difficult to ascribe relative merit to the different pore sizes. It appears that little change is actually observed for the various filter sizes as shown in Figure 11.

The zinc that has been used in the heating experiments exhibit some interesting features. There is a significant amount of agglomeration and some evidence of oxidation. These features can be seen in Figure 12. The shiny metallic sheen of the as-received condition is not apparent after the zinc has been heated several times.

\section{Discussion and Conclusion}

The pumping efficiency was adversely affected by filters with pore diameters of $1 \mu \mathrm{m}$ and $0.2 \mu \mathrm{m}$. Based on these results and the effects of scale for the TEF, it is inadvisable to reduce the pore filter size to these dimensions. There was no apparent effect on either ultimate pressure achieved or pumping time for the filters with 5,10 , or $20 \mu \mathrm{m}$ pore diameters for this system.

The zinc trapping efficiency for the nominal 2 hour exposure at a mantle temperature of $400^{\circ} \mathrm{C}$ did not seem to vary with pore diameter. For the series of experiments conducted, the weight gains varied from about $1.5 \mathrm{mg}$ to $2.9 \mathrm{mg}$. There was no direct relationship between the pore diameter and weight gain. 
There was a correlation between the time at temperature and the weight gain with increased time, nominally one hour to two hours, resulting in about a doubling of the weight for the $20 \mu \mathrm{m}$ filters. The age of the zinc and the amount of previously volatized zinc may also affect how much zinc was deposited, but this variable was not directly controlled.

The $20 \mu \mathrm{m}$ pore filter media that is currently used at SRS is a suitable filter material for to utilize for future extractions. There is evidence that smaller pore filter will adversely affect the pumping times for the TEF and little evidence to suggest that smaller pore diameter filters offer improved zinc trapping efficiency.

\section{References}

1. SRNL-L7100-2010-00019, Zn-65 Trapping and Containment Optimization, P. Korinko, 5/2010

2. TTP-1-3003, White paper to Address Contamination Issues in TEF, E.F. Love, 2008.

3. SRNL-L7100-2008-00001, Analysis of TEF Pipe with Zn-65 Contamination P. Korinko, M. Tosten, Z. Nelson, 9/2008

4. SRNL-L7100-2010-00008, Examination of TEF Filters for 65Zn Trapping, Paul Korinko, Michael Tosten, Zane Nelson, 2/2010

5. SRNL-LM200-2009-00013, Recommendations for TEF to Minimize Further Contamination of ${ }^{65} \mathrm{Zn}$, Paul Korinko, Robert Malstrom, and Andrew Duncan, 4/2009

6. SRNL-L7100-2010-00034, Examination of New Filter Media used for Zn Coalescing Filters, Paul Korinko, 8/2010

7. SRNL-L7100-2010-00039, Zinc Deposition R\&D Direction, P. Korinko, 11/2010 
Table 1. Test Condition and results

\begin{tabular}{|l|l|l|l|l|}
\hline Filter & Vessel Temp $\left({ }^{\circ} \mathrm{C}\right)$ & Time $\mathrm{T}>300^{\circ} \mathrm{C}(\mathrm{s})$ & $\Delta$ mass $(\mathrm{mg})$ & Comments \\
\hline $0.2 \mu \mathrm{m}-1$ & 333 & 3965 & 0.40 & Old Config. \\
\hline $20 \mu \mathrm{m}-4$ & 340 & 3954 & 1.31 & Old Config. \\
\hline $20 \mu \mathrm{m}-5$ & 330 & 4192 & 1.04 & New Config. T varied \\
\hline $0.2 \mu \mathrm{m}-2$ & 330 & 7492 & 2.89 & New Config \\
\hline $1 \mu \mathrm{m}-1$ & 325 & 7613 & 1.73 & New Config used Zn \\
\hline $5 \mu \mathrm{m}-1$ & 320 & 6613 & 2.57 & New Config used Zn \\
\hline $10 \mu \mathrm{m}-1$ & 324 & 7689 & 1.49 & New Config used Zn \\
\hline $20 \mu \mathrm{m}-6$ & 325 & 7546 & 1.82 & New Config used Zn \\
\hline $20 \mu \mathrm{m}-7$ & 350 & 8169 & 2.14 & New Config New Zn \\
\hline $20 \mu \mathrm{m}-8$ & & & & \\
\hline
\end{tabular}



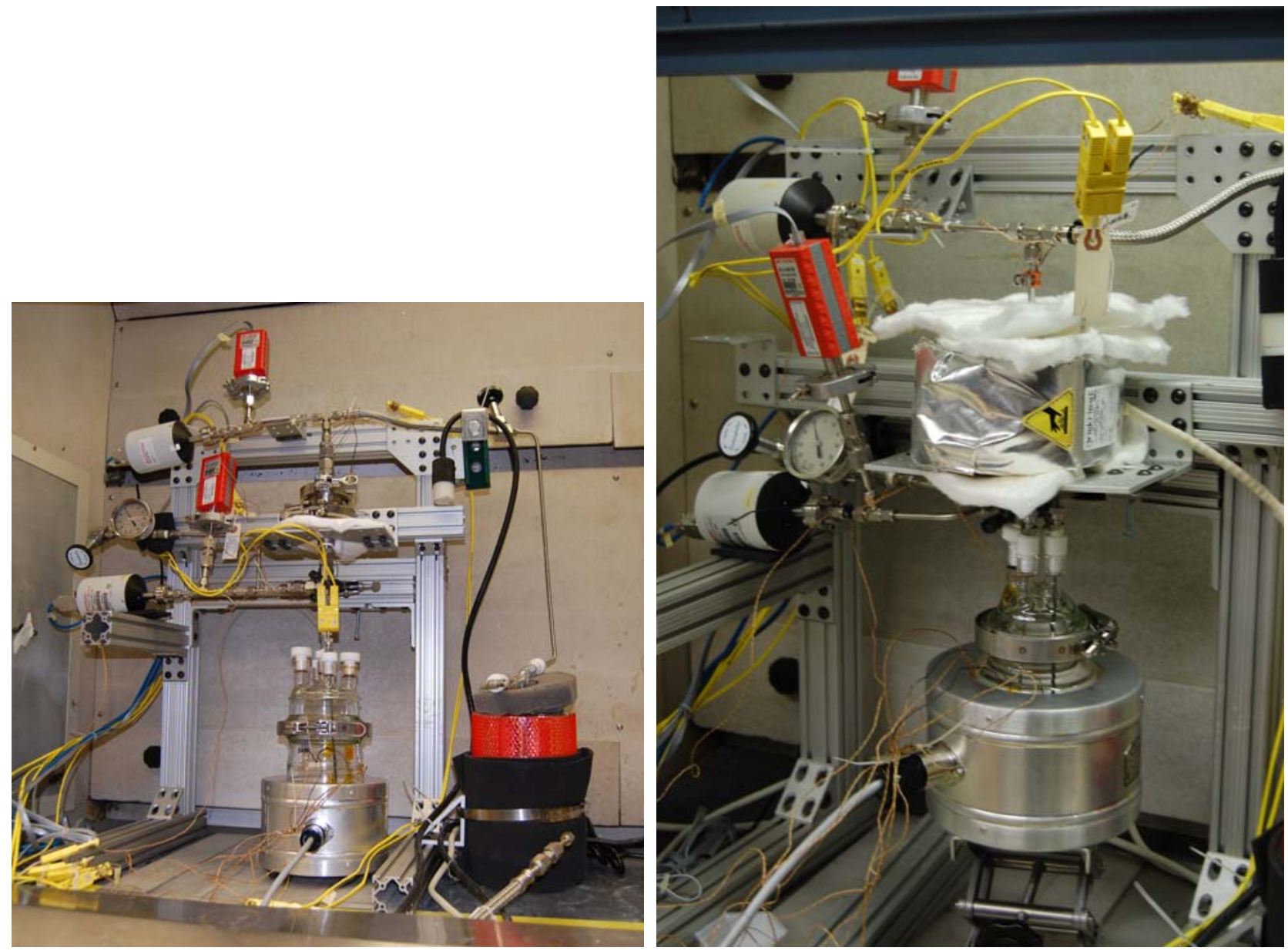

Figure 1. Photographs of zinc TVD apparatus, initial and final configurations, installed in chemical hood. 


\section{Average Pump Down Curves}

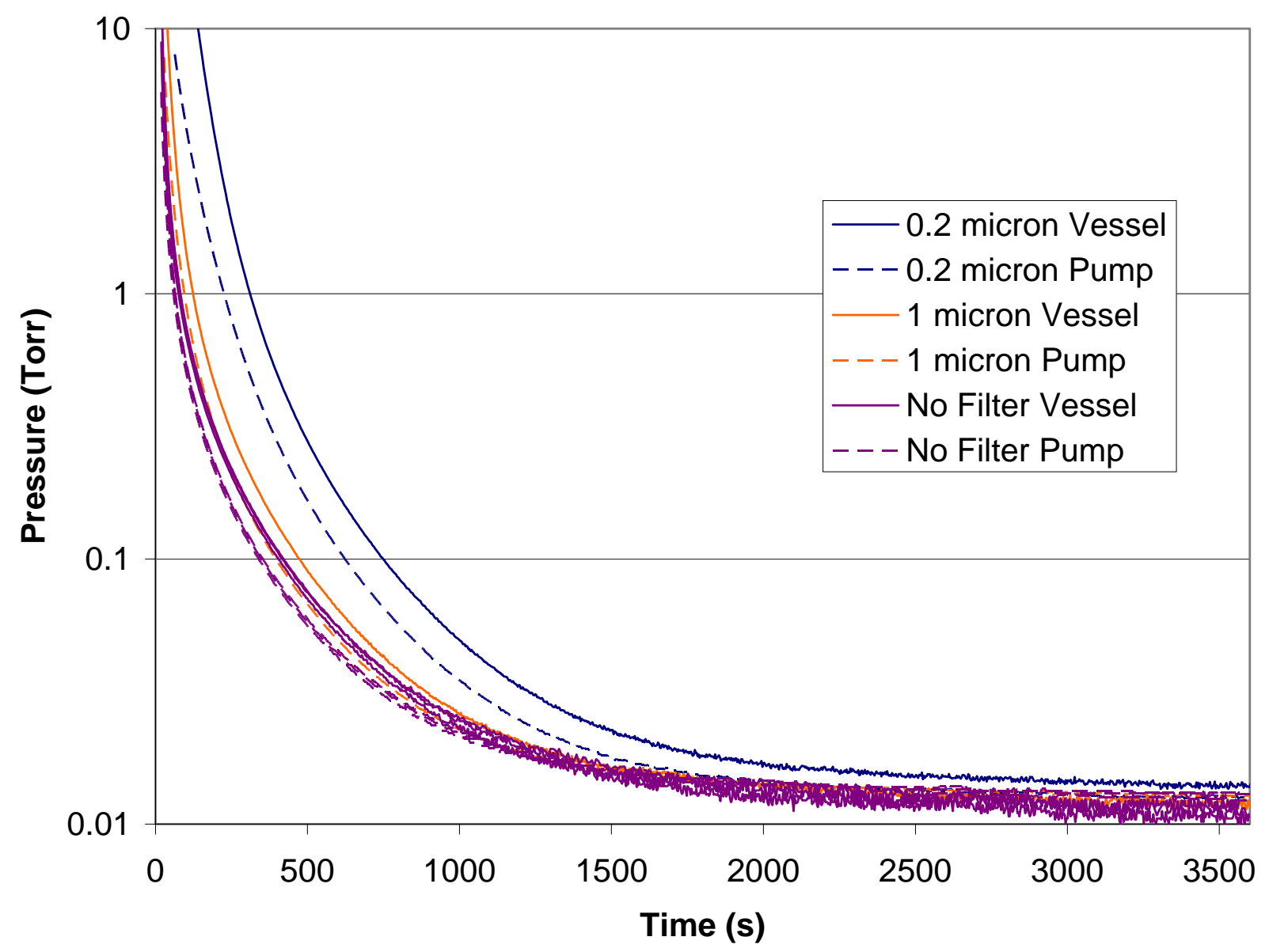

Figure 2. Evacuation times for the original apparatus with filters of $0.2 \mu \mathrm{m}$ and $1 \mu \mathrm{m}$ installed. 
Average Pump Down Curves

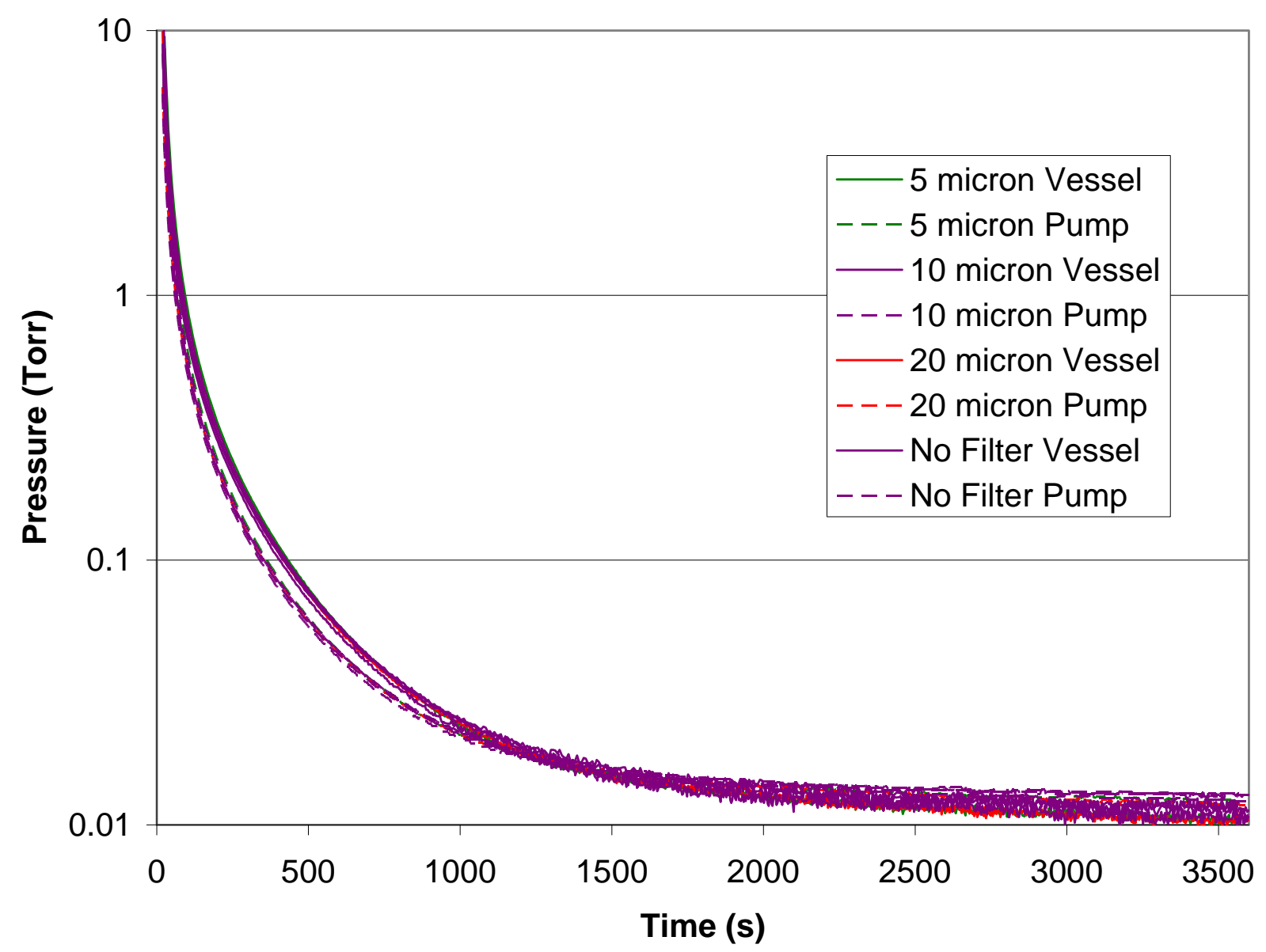

Figure 3. Evacuation times for the original apparatus with filters with 5, 10, and $20 \mu \mathrm{m}$ installed. 
$20 \mathrm{~mm} \mathrm{400C} \mathrm{200C} \mathrm{Filter}$

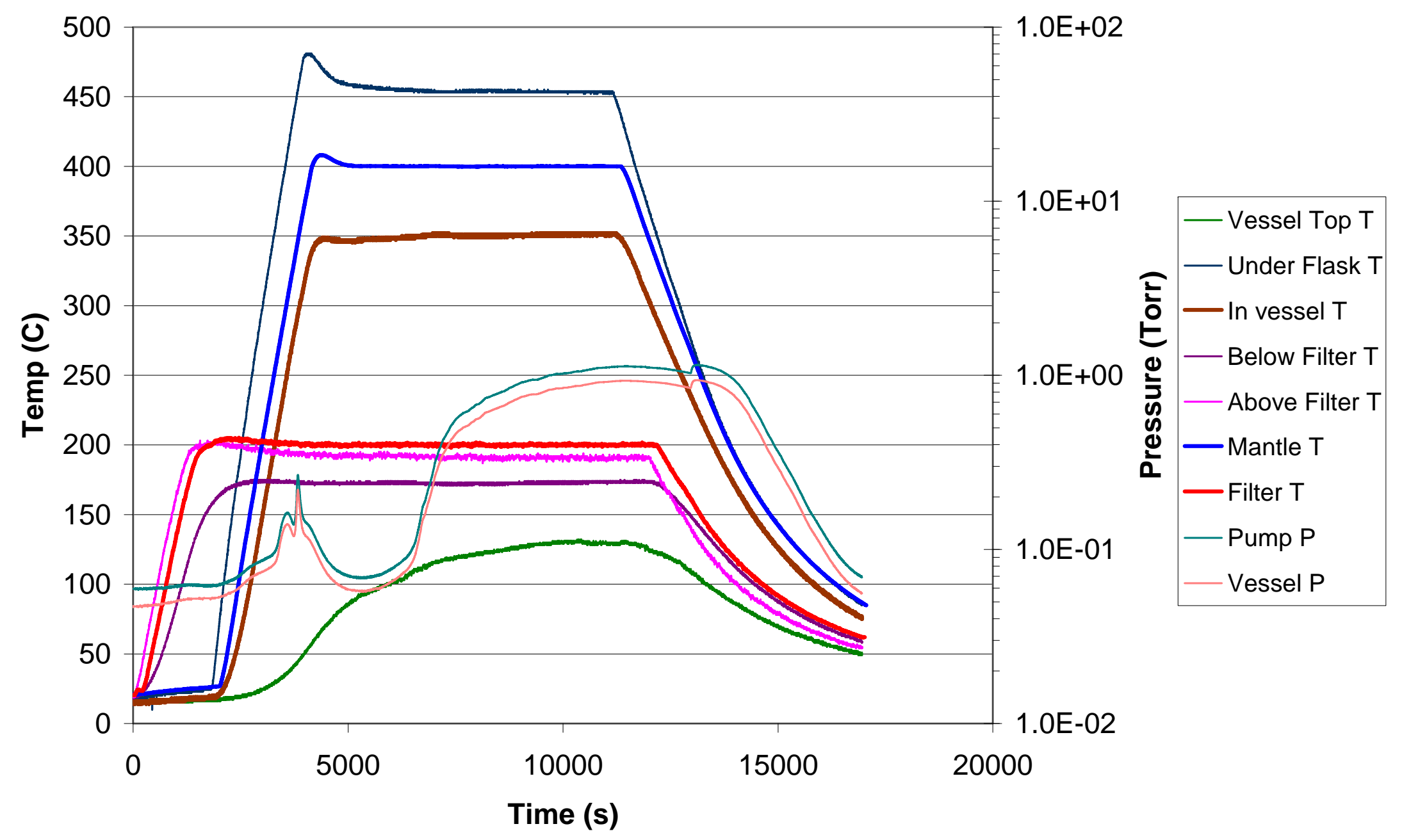

Figure 4 Typical data for the experimental evolution starting with filter element heating. 


\section{Pressure and Temperature Comparison}

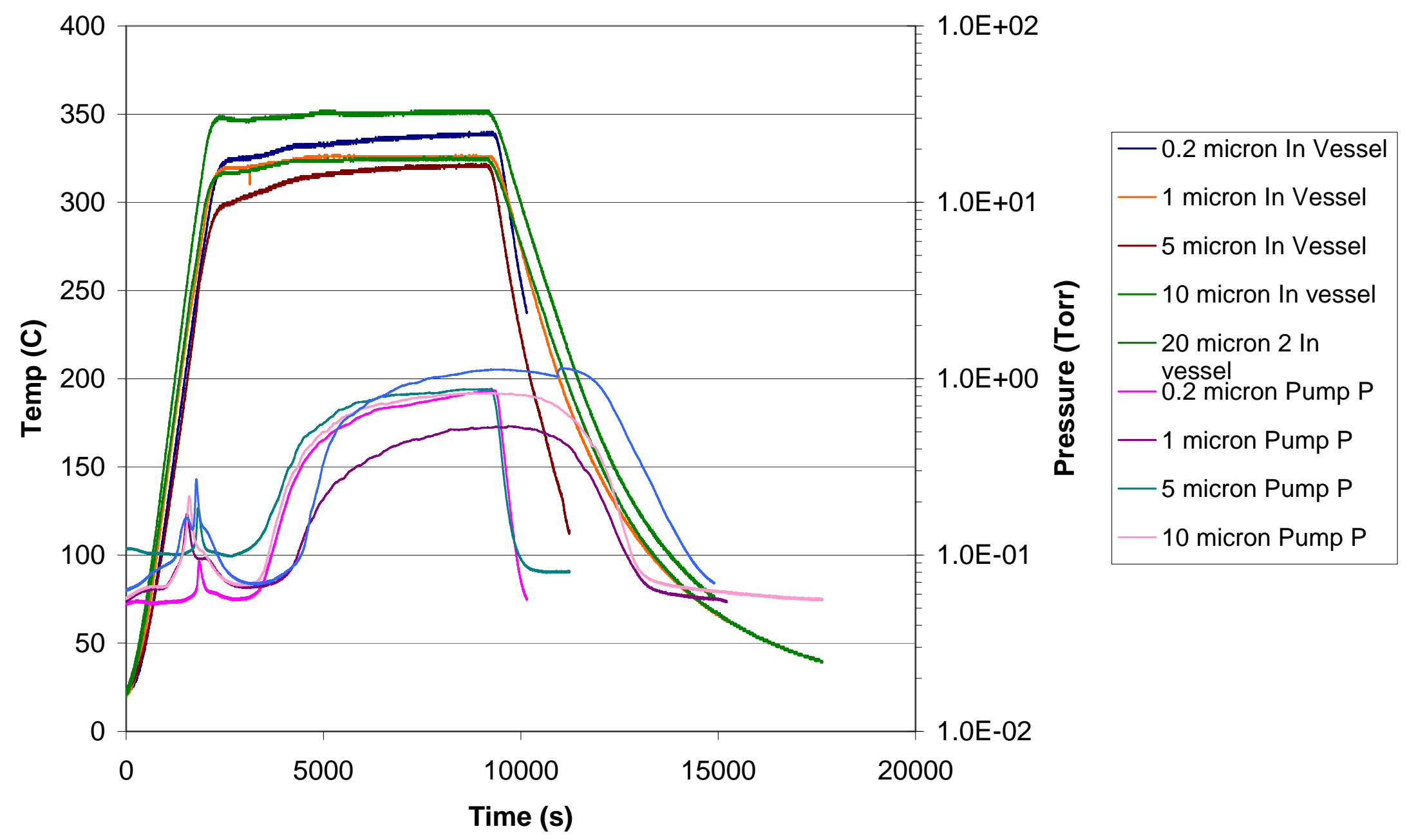

Figure 5. Comparison data from all five sized filter pores. 


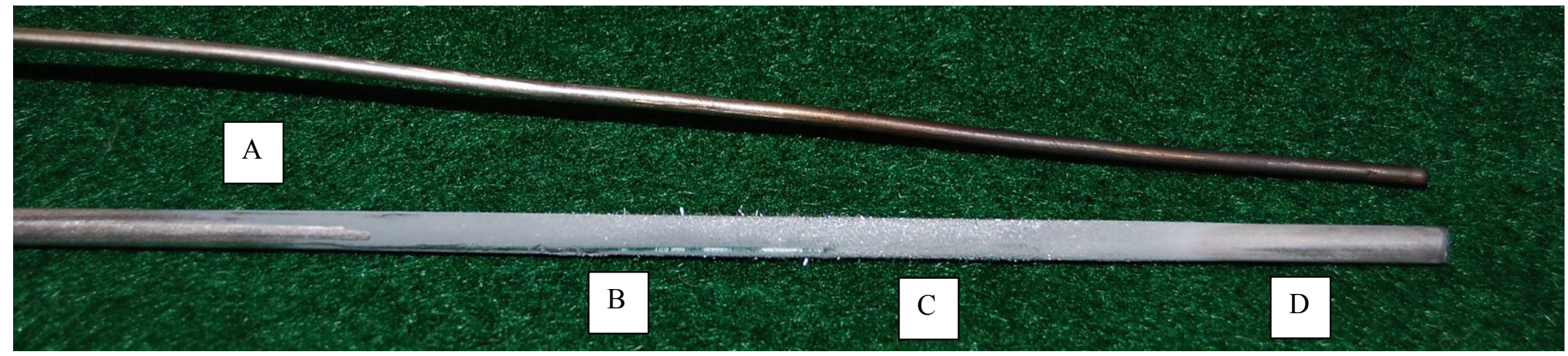

Figure 6. Macrograph of a rod exposed to the vapor and temperature gradient in TVD \#1. Letters indicate areas of higher magnification images in Figure 7. 

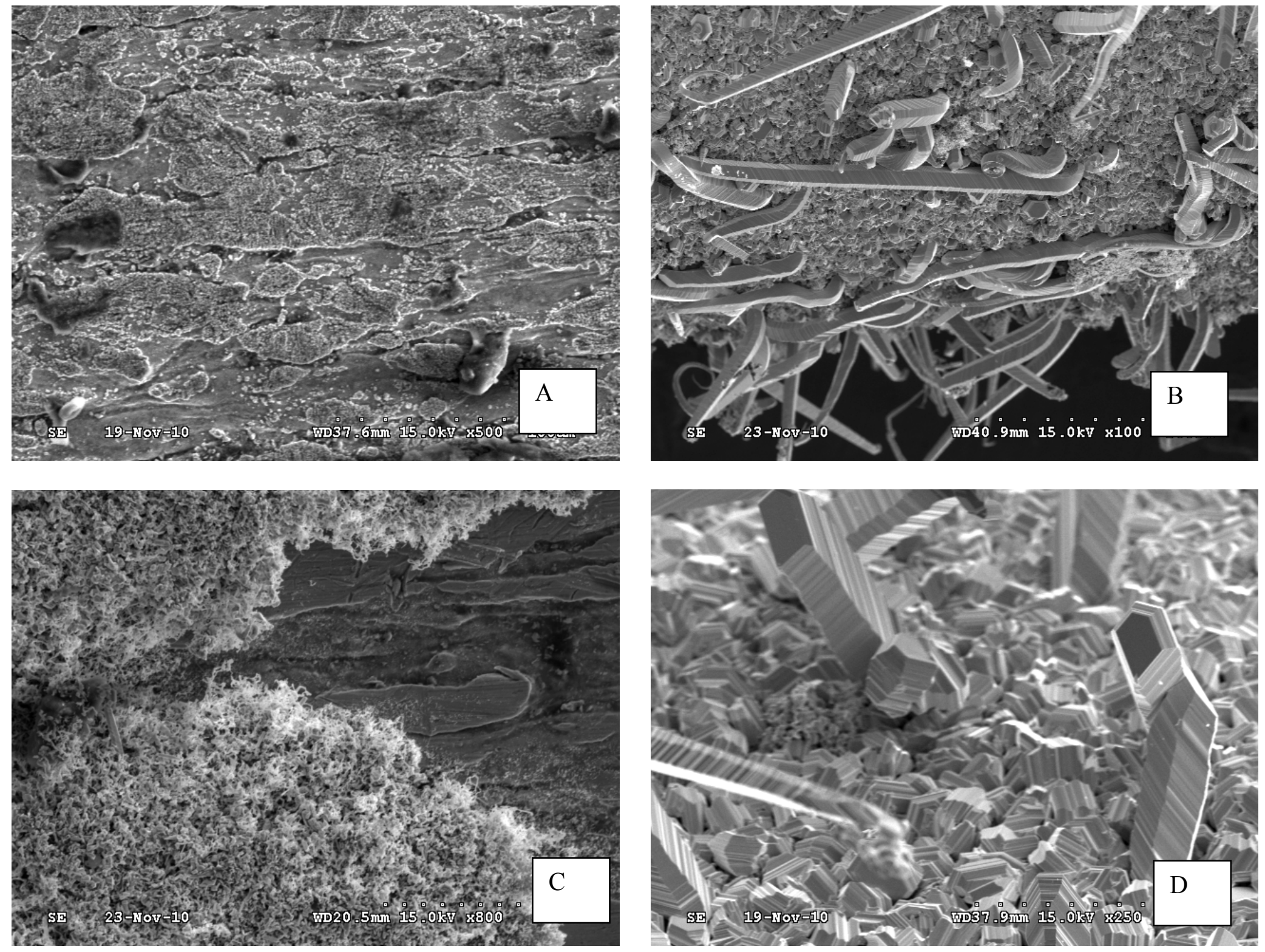

Figure 7. Higher magnification of the various morphologies on the rod. 


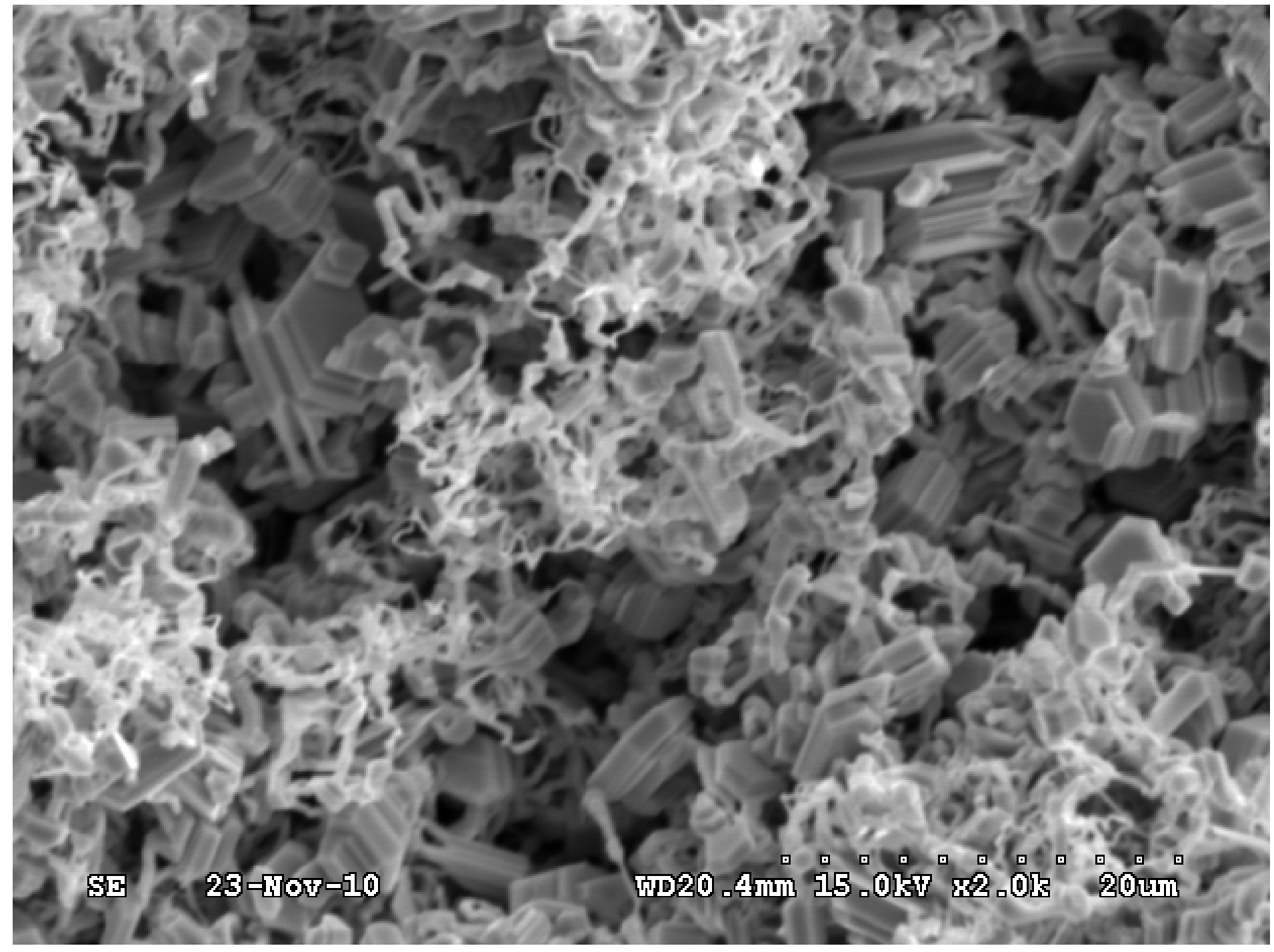

Figure 8. Higher magnification of area "D" showing the mixed mode growth at the cool end of the rod. 

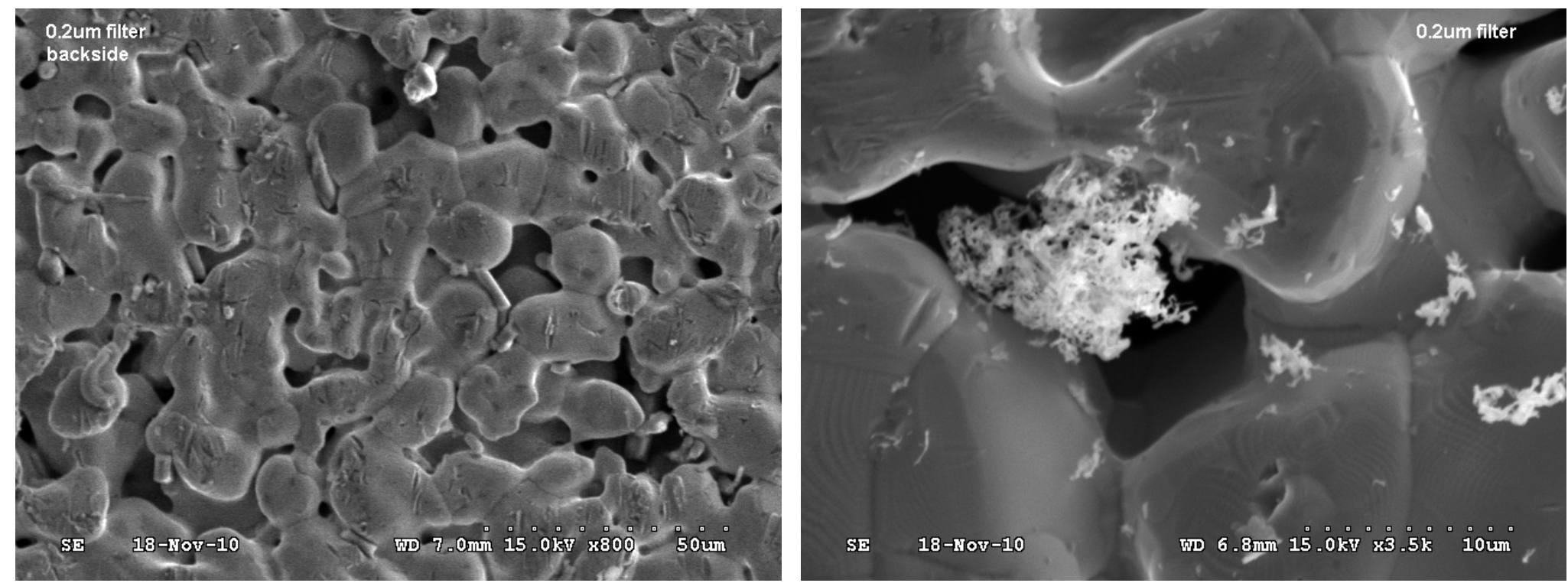

Figure 9. Zn deposit structure on the center of the $0.2 \mu \mathrm{m}$ filter disk. 

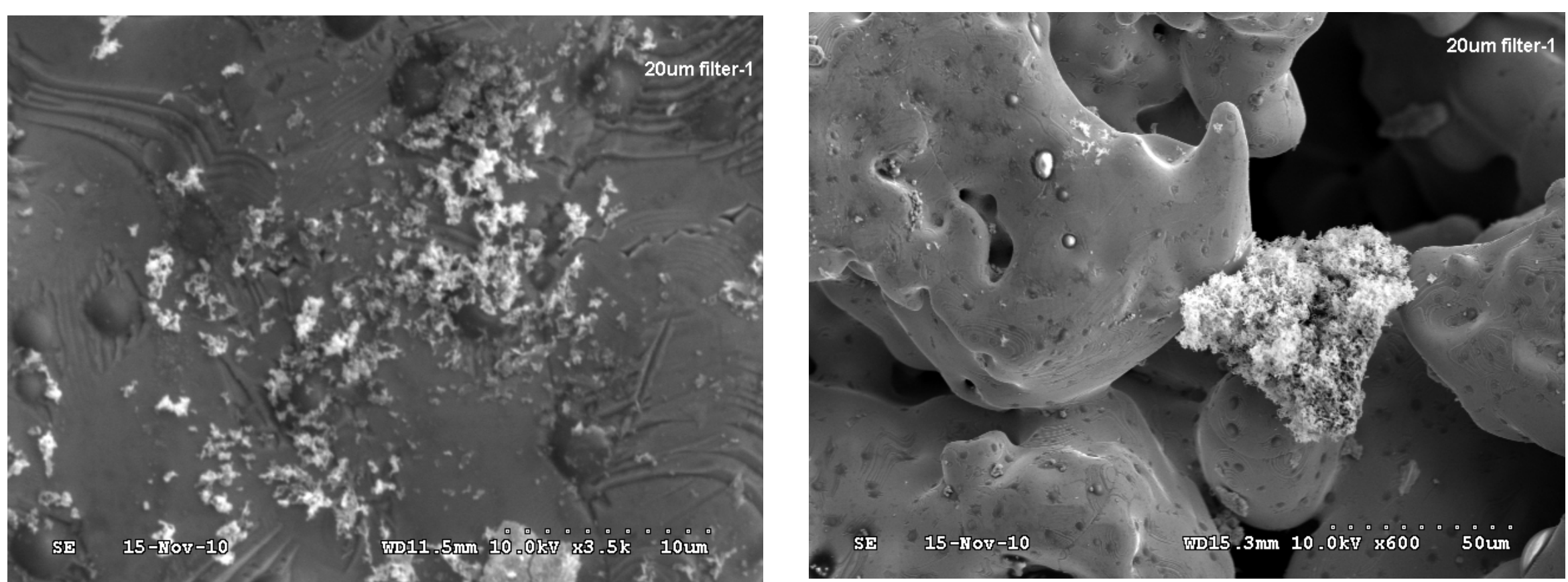

Figure 10. Zn deposit structure on the $20 \mu \mathrm{m}$ filter disk.

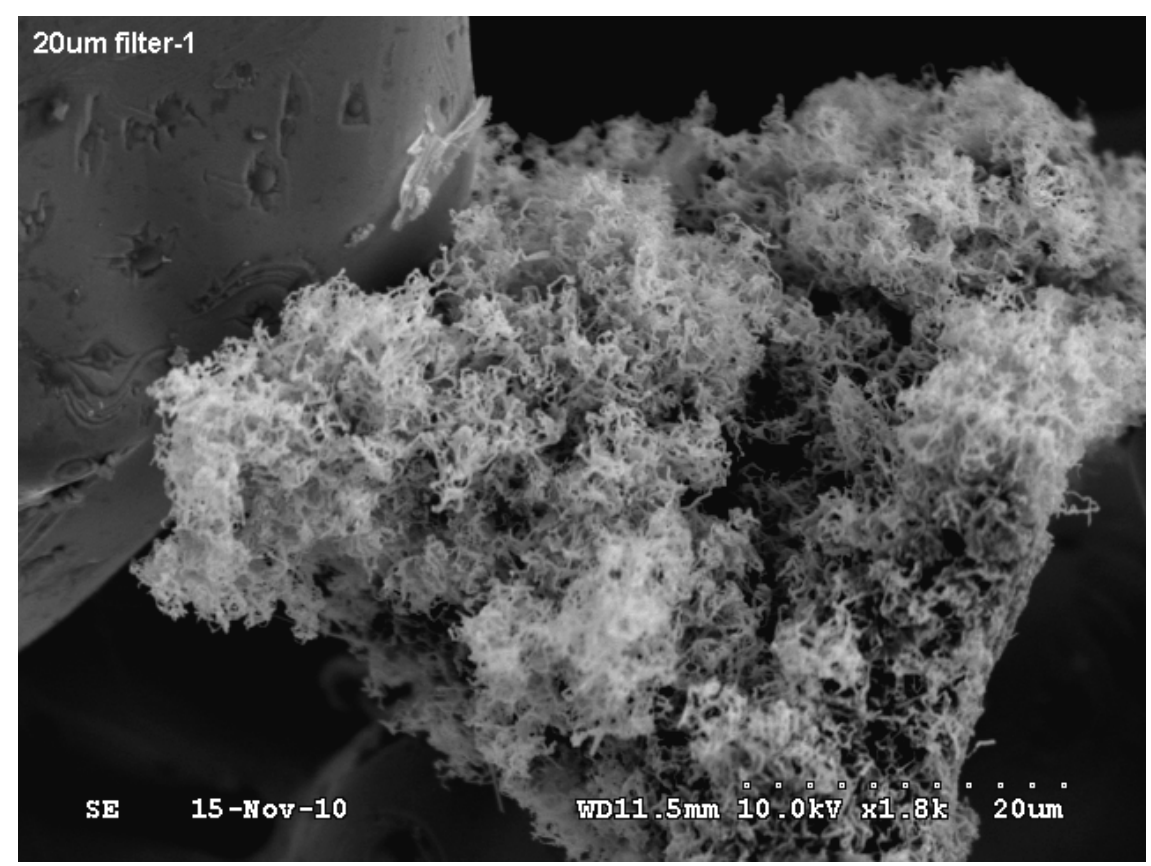




\section{Filter Size Effects}

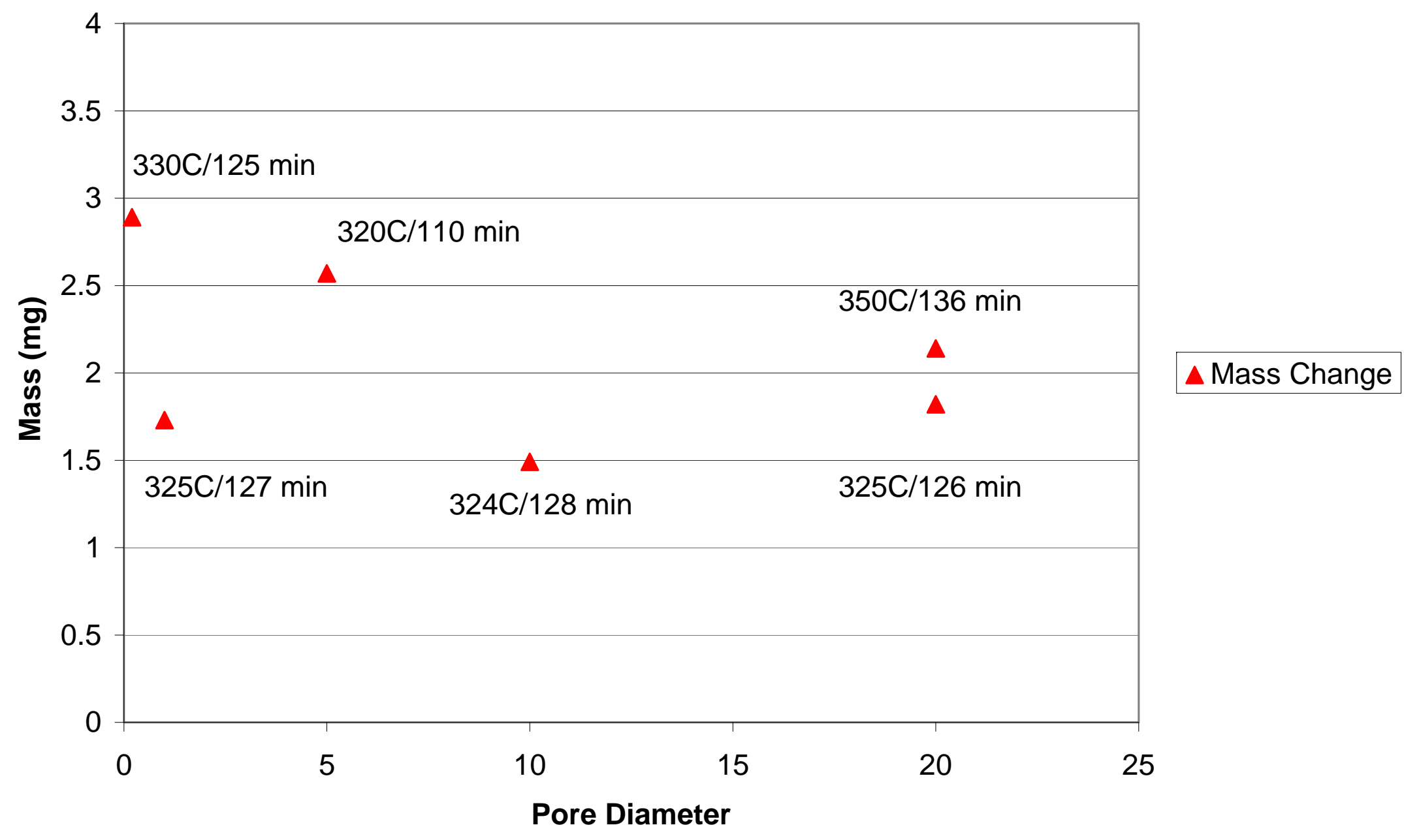

Figure 11. Plot of mass change as function of pore size with experimental conditions also indicated. 

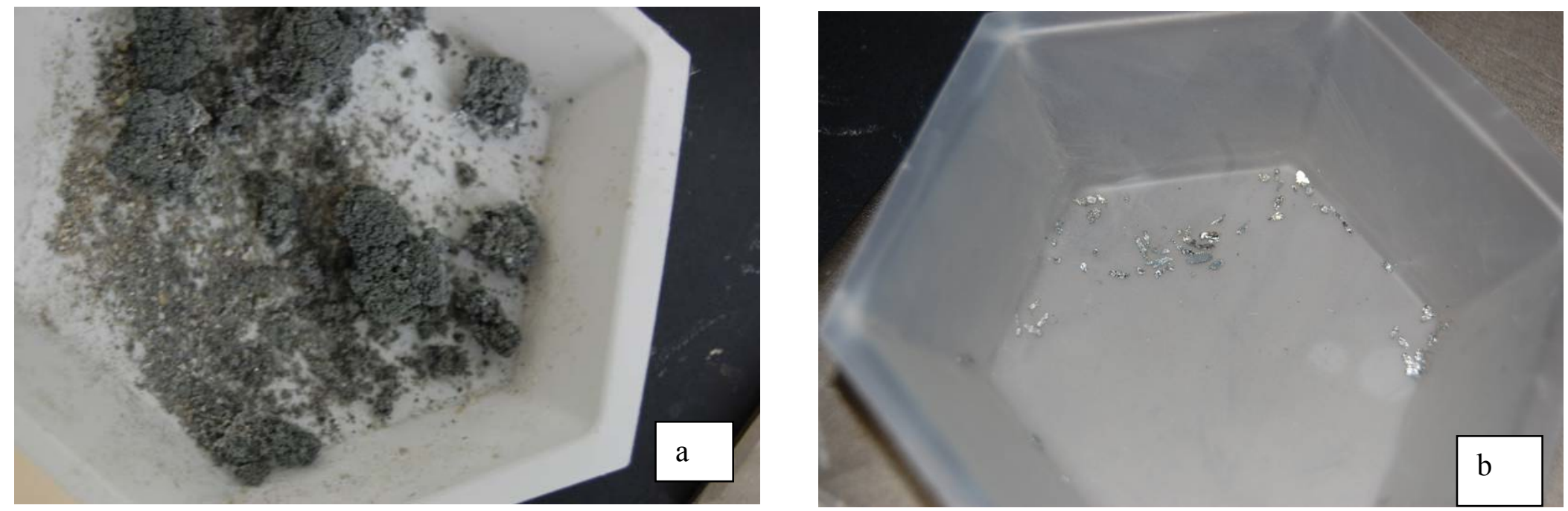

Figure 12. Condition of thermally treated zinc (a) and as received (b) zinc. 